\title{
Genetic engineering of sweet potatoes (Ipomoea batatas) using isopentenyl transferase gene for enhanced drought tolerance
}

\author{
SYLVIA OBINDA NAWIRI, RICHARD OKOTH ODUOR", ALLAN MGUTU JALEMBA \\ Department of Biochemistry and Biotechnology, Kenyatta University. P.O. Box 43844 Nairobi, Kenya, `email: oduor.richard@ku.ac.ke
}

Manuscript received: 14 August 2017. Revision accepted: 26 December 2017.

\begin{abstract}
Nawiri SO, Oduor RO, Jalemba AM. 2017. Genetic engineering of sweet potatoes (Ipomoea batatas) using isopentenyl transferase gene for enhanced drought tolerance. Asian J Agric 1: 85-99. Approximately 70\% of yield crop reduction worldwide is caused by drought. Due to severe drought, which happens often as a result of climate change, substantial yield deprivation is usual among the major cereals such as maize, wheat, and barley. Therefore, drought tolerant crops that still yield amidst erratic climatic phenomena are greatly needed. Due to its capability to produce high yield in a short period, sweet potato is suitable for cultivation in regions with limited or erratic rainwater supply where other food crops cannot grow easily. Nevertheless, its sensitivity to water deficit may lead to adverse crop growth and yield. By conventional hybridization method, sweet potato is tried to be improved, but it gives unsatisfied results due to its high male sterility, sexual incompatibility and hexaploidy nature of its genome. The aim of this study, therefore, is to develop new varieties of sweet potato with improved tolerance to water-deficit stress for sustainable production of sweet potato under water-limited conditions. Three sweet potato genotypes: Jewel, Kemb36, and Ksp36 were transformed using isopentenyl transferase gene (IPT) that delays drought-induced senescence via up-regulation of cytokinin biosynthesis, under the control of a waterdeficit responsive and maturation specific promoter (PSARK). The PNOV-IPT gene construct was introduced into sweet potatoes to evaluate their transformability and regenerability. It was done via Agrobacterium tumefaciens strain EHA101 and the plants subsequently regenerated via somatic embryogenesis. Jewel genotype recorded the highest transformation and regeneration frequency, followed by Kemb36 and KSP36. Calli were cultured on media supplemented with various mannose concentrations to evaluate the suitability of mannose as a selectable marker for sweet potato, and it was discovered that $30 \mathrm{~g} / \mathrm{L}$ concentration was optimal for selection of transformed events. At the time of PCR analysis, Jewel had the highest transformation efficiency followed by Kemb36. At the time for evaluation on drought tolerance under controlled conditions, the sweet potato showed delayed senescence and greater drought tolerance under water deficit conditions in the glasshouse. These plants exhibited better growth, higher yield, higher water status maintenance, higher chlorophyll content, and thus higher photosynthetic rates under reduced water conditions in comparison to wildtype. These results, therefore, indicated that expression of isopentenyl transferase gene in sweet potato significantly improves drought tolerance. Therefore, IPT gene should be used to transform other economically important food crops to delay drought-induced senescence and enhance drought tolerance.
\end{abstract}

Keywords: Drought tolerance, genetic engineering, Ipomoea batatas, isopentenyl transferase gene

\section{INTRODUCTION}

Sweet potato (Ipomoea batatas (L.) Lam.) is a perennial, herbaceous dicotyledonous species belonging to the order Polemoniales and the family Convolvulaceae (Mervat et al. 2009). The crop is ranked as the world's seventh most important food crop after wheat (Triticum aestivum), rice (Oryza sativa), maize (Zea mays), potato (Solanum tuberosum), barley (Hordeum vulgare), and cassava (Manihot esculenta Crantz.) (Kim et al. 2010). Sweet potato is grown in more than 110 countries, on an area estimated at 8.5 million hectares (Placide et al. 2013). In Africa, the area under sweet potato cover is estimated at $1,714,000$ hectares. The annual global production of sweet potato is estimated at 106.5 million metric tonnes and out of this, $15 \%$ of the annual production is from Eastern and Central Africa. China is the highest producer of sweet potato at $80 \%$ of the total of the world annual production, followed by Nigeria and Uganda (FAOSTAT 2010).

Sweet potato is an economically important crop in tropical, subtropical, and warm temperate regions (Mervat et al. 2009). It is a valuable source of food, animal feed and industrial raw material (Anwar et al. 2010). The crop is known as "the crop of the twenty-first century" because it represents a potential new source of energy. The storage roots of sweet potatoes have high a carbohydrate content that ranges between $80-90 \%$ of their dry weight. The carbohydrates consist mainly of starch, sugars, and a low quantity of pectin, hemicelluloses, and cellulose (Lebot 2009). The high energy levels of sweet potato, make it an attractive industrial raw material for biodegradable plastics and for biofuel production (Placide et al. 2013).

The presence of trypsin inhibitor is found in sweet potato, and thus has several medicinal benefits, along with the major storage root of protein. Trypsin inhibitor has antioxidant activity; it inhibits angiotensin converting enzyme activity, growth, and induction of apoptosis in NB4 promyelocytic leukemia cells (Chen et al. 2010). The antioxidant compounds such as anthocyanin, carotenoids, and vitamin $C$ (Teow et al. 2007) have attracted special attention because they can protect the human body from oxidative stress reactants, which may promote aging and many diseases including cancer (Halliwell 2007; Luceri et al. 2008) 
Facing a global undersupply of water, appropriate action should be done to overcome this problem, especially on the sweet potato plantation. This plant is relatively drought tolerant, but at the stage of growth and development, this plant is susceptible to drought. Conventional sweet potato proliferation can improve drought tolerance, but requires a long time to select suitable plants. In recent years, with the rapid development of plant gene engineering, it has become feasible to improve crops using transgenic technology (Liu et al. 2008; Wang et al. 2008; Cao et al. 2009). Several attempts have shown that an enhanced tolerance to drought in sweet potato can be achieved through introduction of genes that encode antioxidant enzymes $(\mathrm{Cu} / \mathrm{Zn}$ superoxide dismutase $[\mathrm{CuZn}$ SOD] and ascorbate peroxidase [APX]) and kinase (nucleoside diphosphate kinase 2 [NDPK2]) (Kim et al. 2009; Lu et al. 2010).

Genes encoding transcription factors have received much attention in recent years, due to their ability to activate stress tolerance genes under drought conditions (Jiang et al. 2010). The DREB/CBF class of transcriptional factors have been found to be effective in conferring drought tolerance (Umezawa et al. 2006; Shinozaki and Yamaguchi-Shinozaki 2007; Yang et al. 2010). Besides progress being made in expressing stress-related transcription factor genes in transgenic plants, several reports indicate that changes in hormone homeostasis, brought about by the expression of isopentenyl transferase (IPT) a key enzyme in the biosynthesis of cytokinin, under the control of a maturation-and stress-induced promoter (PSARK), resulted in enhanced drought tolerance (Rivero et al. 2007; Rivero et al. 2009; Rivero et al. 2010).

To regenerate IPT transgenic sweet potato lines, Agrobacterium tumefaciens-mediated transformation was used in this study. Overexpression of IPT gene in sweet potato led to significantly enhanced drought tolerance, showing the potency to develop drought stress-tolerant cultivars of this crop. The pathway involves the transfer of isopentenyl group from the dimethylallyl diphosphate (DMAPP) to the N6 of AMP resulting in the production of isopentenyl adenosine-5-monophosphate (iPMP). This reaction is catalyzed by DMAPP: AMP isopentenyl transferases (Kakimoto 2001).

The objectives of this research were (i) To transform and regenerate sweet potato varieties Kemb36, KSP36 and Jewel for enhanced drought tolerance using isopentenyl transferase (IPT) gene. (ii) To evaluate the effect of explant used on transformation and regeneration. (iii) To evaluate effectiveness of phosphomannose isomerase as a selectable marker for generation of transgenic sweet potato events. (iv) To evaluate the performance of IPT expressing transgenic sweet potato varieties under drought stress.

\section{MATERIALS AND METHODS}

\section{Source of explants}

This study used two Kenyan sweet potato cultivars, i.e., Kemb36, KSP36 obtained from Kenya Agricultural Research Institute (KARI) and one non-African cultivar, i.e., Jewell obtained from International Potato Centre (IPC) after virus indexing as observation materials. These plants were grown under greenhouse conditions at Kenyatta University. The plants were allowed to grow for two months before being used as stock plants for subsequent regeneration experiments.

\section{Surface sterilization}

Stem cuttings were accumulated from healthy vines from the potted sweet potato in the glasshouse and the leaves were removed. The stem pieces were then cut into 2 $\mathrm{cm}$ long nodal cuttings, each having a bud (Figure 1.A). The vines were cleansed thoroughly under running water to remove any loose dirt on the surface. This was followed by soaking them in $70 \%(\mathrm{v} / \mathrm{v})$ ethanol for $3 \mathrm{~min}$ and then finally soaking in $2.5 \%(\mathrm{v} / \mathrm{v})$ sodium hypochlorite (JIK) containing 2-3 drops of Tween 20 for 20 minutes with occasional shaking under sterile conditions in the laminar floor (Njagi 2004). To remove the sodium hypochlorite, the stems were rinsed in sterile distilled water then blot dried using Whatman filter papers (CAT No. 1001090 Whatman International limited England). The damaged parts were removed using a sterile scalpel and were now ready for propagation experiment.

\section{In-vitro propagation of sweet potato}

In-vitro plants were cultured on sweet potato propagation media, as per the procedure described by Luo et al. (2006). Two sterile nodal segments, with at least two nodes, were cultured in universal culture bottles containing $80 \mathrm{~mL}$ of sweet potato propagation medium (Figure 1.B). The cultures were incubated in the growth room at $28^{\circ} \mathrm{C}$, $16 / 8 \mathrm{~h} \mathrm{light/dark}$ photoperiod, $70 \%$ relative dampness and 3,000 light intensities supplied by fluorescent bulbs for 3-5 weeks. The cultures were kept in the growth room as invitro source of clean explants for regeneration and transformation experiments (Figure 1.C) and were subcultured after every 5 weeks to keep an adequate supply of clean mother plants (Figure 1.D).

\section{Determination of optimal mannose concentration for selection of transformed sweet potatoes}

Four-week-old leaf explants from the in-vitro plants were used to evaluate the impact of mannose on callus proliferation and embryo development on callus induction medium supplemented with different carbohydrate sources. First, the explants were put on callus induction medium to initiate calli. Upon callus formation, the young calli were displaced to selection medium containing varying concentrations of mannose. The callus induction medium was divided into four equal parts and different concentrations $(1 \%, 2 \%, 3 \%$, and $4 \% \mathrm{w} / \mathrm{v})$ of mannose added. Callus induction medium with $30 \mathrm{~g} / \mathrm{L}$ of sucrose was used as positive control while one without sucrose was used as a negative control. Cultures were maintained in the dark at $27 \pm 1^{\circ} \mathrm{C}$ for 12 weeks then subcultured on the same substrate medium after every two weeks. During subculturing, callus proliferation and aspect (color, consistency, and hydration) were qualitatively evaluated. 


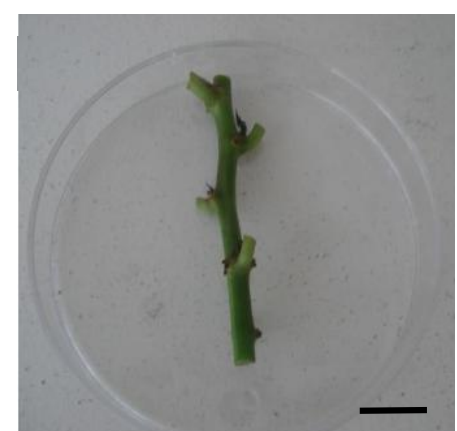

A

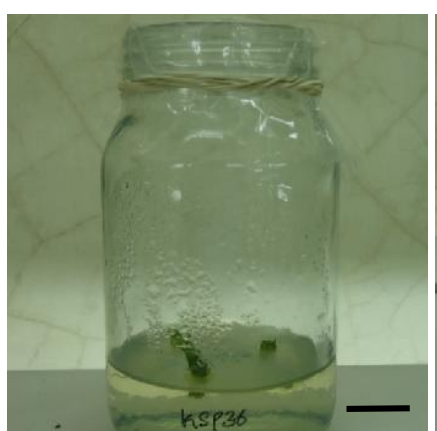

B

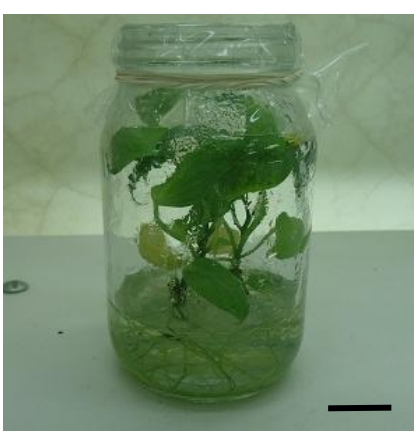

C

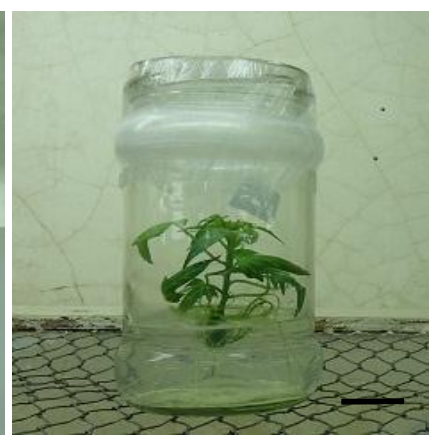

D

Figure 1. In-vitro propagation of sweet potato. A. Jewel nodal stem before propagation. B. KSP36 nodal stems in sweet potato propagation media 3 days after incubation. C. Fully established Jewel in-vitro plant. D. Kemb36 in-vitro plant after 4weeks on propagation media $($ bar $=2 \mathrm{~cm})$.

\section{Bacterial strains and plasmid}

Agrobacterium tumefaciens strain EHA 101 harboring binary plasmid vector pNOV-IPT was used in this study. The pNOV-IPT binary vector contained IPT gene driven by SARK promoter. This gene construct also harbored a $P M I$ gene as a selectable marker gene encoding phospomannose Isomerase enzyme that confers resistance to mannose in positively transformed tissues. The IPT gene was a kind donation by Dr. Edwardo Blumwald from the University of California Davis, USA.

\section{Maintenance of Agrobacterium tumefaciens strain EHA101 harboring PNOV-IPT gene construct}

Agrobacterium tumefaciens strain EHA101 carrying the $I P T$ gene construct was initiated form stock plates stored for less than two weeks at $4^{\circ} \mathrm{C}$ and maintained on $\mathrm{LB}$ medium (Duchefa, Netherlands) supplemented with $100 \mathrm{~m}$ $\mathrm{g} / \mathrm{L}$ kanamycin and $100 \mathrm{~m} \mathrm{~g} / \mathrm{L}$ spectinomycin (Figure 2). The plasmids were refreshed every three weeks.

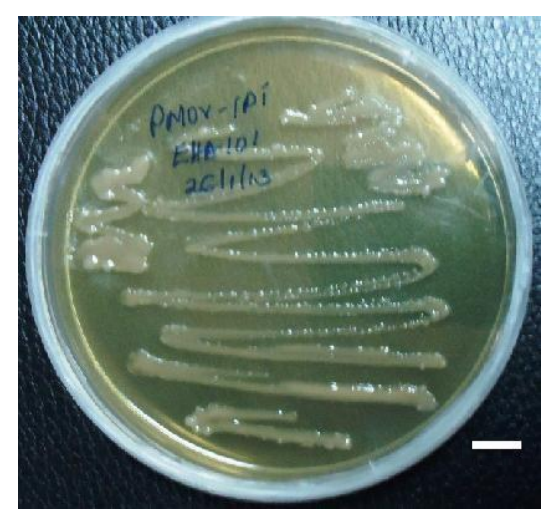

Figure 2. Maintenance of plasmid gene constructs bearing PSARK-IPT gene on LB media $($ Bar $=1 \mathrm{~cm})$

\section{Infection and Co-cultivation of sweet potato explants}

A loopful of $A$. tumefaciens strain EHA101 harboring pNOV-IPT gene construct from 48-h cultured LB agar plates was used to inoculate $50 \mathrm{~mL}$ of standard LB liquid media containing kanamycin at $50 \mathrm{~m} \mathrm{~g} / \mathrm{L}$ and spectinomycin at $50 \mathrm{~m} \mathrm{~g} / \mathrm{L}$. These were then put on a shaker $(200 \mathrm{rpm})$ at $28^{\circ} \mathrm{C}$ for $48 \mathrm{~h}$ to grow. A $2 \mathrm{~mL}$ aliquot of the 3-day bacterial culture was displaced into a $50 \mathrm{~mL}$ falcon tube with $20 \mathrm{~mL}$ LB media containing kanamycin and spectinomycin. This was put on a shaker $(200 \mathrm{rpm})$ at $28^{\circ} \mathrm{C}$ until $0.4-0.6$ at $600 \mathrm{~nm}$ optical density of culture was obtained. Bacterial cells were then centrifuged at 3,000 rpm for $10 \mathrm{~min}$ at $4^{\circ} \mathrm{C}$ to obtain the bacteria pellet. The supernatant was poured out and the pellets resuspended with $20 \mathrm{~mL}$ of bacterial infection media (MIB). Before infection of the explants, the leaf and stem explants were first put on a preculture media and incubated at $28^{\circ} \mathrm{C}$ for 2 days (Figure 3.A). For infection, leaf and stem explants were submerged in $10 \mathrm{~mL}$ of MIB with the strain EHA101 and kept for $2 \mathrm{~h}$ in the dark at $28^{\circ} \mathrm{C}$ without agitation. Finally, the infected explants were removed from the infection media, blot dried using sterile filter papers and displaced to a co-cultivation media (Table 1) at $28^{\circ} \mathrm{C}$ for 3 days in the dark (Figure 3.B).
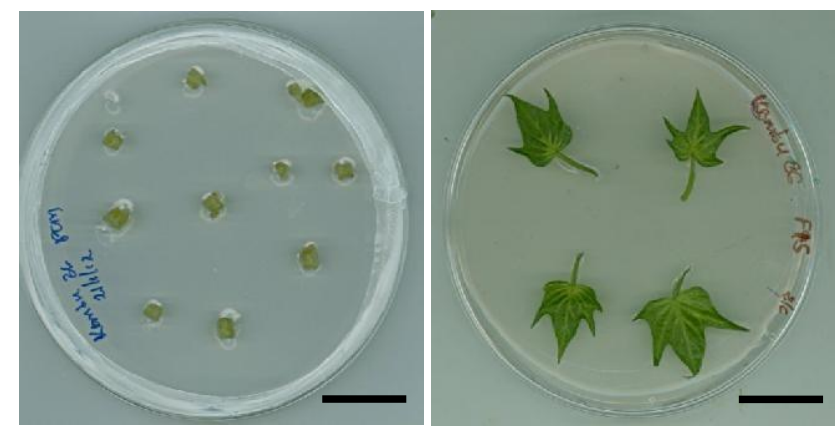

Figure 3. Sweet potato transformation. A. Kemb36 stem explants on preculture media $12 \mathrm{~h}$ before infection. B. Kemb36 leaf explants from the in-vitro cultures on co-cultivation media after infection $(\mathrm{Bar}=2 \mathrm{~cm})$. 
Table 1. Composition of culture media and transformation and regeneration protocol of sweet potato.

\begin{tabular}{|c|c|c|c|c|c|}
\hline $\begin{array}{l}\text { Media } \\
\text { preparation }\end{array}$ & Stage & Basic composition & $\begin{array}{l}\text { Hormones and } \\
\text { antibiotics }\end{array}$ & $\begin{array}{l}\text { Concentration } \\
\mathrm{m} \text { g/L }\end{array}$ & $\begin{array}{l}\text { Treatment } \\
\text { period }\end{array}$ \\
\hline EPM & Preinfection & $\begin{array}{l}\text { LS, sucrose, } \\
\text { MES }(0.5 \mathrm{~g} / \mathrm{L}) \\
\text { pH } 5.5\end{array}$ & $\begin{array}{l}\text { NAA } \\
\text { GA3 } \\
\text { BAP }\end{array}$ & $\begin{array}{ll}0.1 \\
0.01 \\
1\end{array}$ & $12 \mathrm{hrs}$ \\
\hline BIM & Infection & LS, sucrose, acetosyringone ( $20 \mathrm{~m} \mathrm{~g} / \mathrm{L}), \mathrm{pH} 5.5$ & N/A & & $2 \mathrm{hrs}$ \\
\hline SCM & Co-culture & $\begin{array}{l}\text { LS, sucrose, glucose }(20 \mathrm{~g} / \mathrm{L}), \text { MES } \\
(0.5 \mathrm{~g} / \mathrm{L}, \mathrm{pH} 5.5\end{array}$ & & & 2 days in dark \\
\hline F15 & $\begin{array}{l}\text { Callus } \\
\text { induction }\end{array}$ & $\begin{array}{l}\text { LS, sucrose, } \mathrm{pH} \\
5.7-5.8\end{array}$ & $\begin{array}{l}\text { Zeatin riboside } \\
2,4-\mathrm{D} \\
\text { Mannose } \\
\text { Cefotaxime }\end{array}$ & $\begin{array}{l}0.2 \\
0.05 \\
30 \\
200\end{array}$ & $\begin{array}{l}5-6 \text { days } \\
\text { then } \\
\text { continue } \\
\text { with F9 }\end{array}$ \\
\hline F9 & $\begin{array}{l}\text { Callus } \\
\text { induction }\end{array}$ & $\begin{array}{l}\text { LS, sucrose, } \mathrm{pH} \\
5.7-5.8\end{array}$ & $\begin{array}{l}\text { Zeatin riboside } \\
\text { Mannose } \\
\text { Cefotaxime }\end{array}$ & $\begin{array}{l}0.2 \\
30 \\
200\end{array}$ & $\begin{array}{l}\text { Until } \\
\text { embryo } \\
\text { form }\end{array}$ \\
\hline G24D* & $\begin{array}{l}\text { Embryo } \\
\text { development }\end{array}$ & $\begin{array}{l}\text { LS, sucrose, } \mathrm{pH} \\
5.7-5.8\end{array}$ & $\begin{array}{l}\text { GA3 } \\
2,4-D \\
\text { Mannose } \\
\text { Cefotaxime }\end{array}$ & $\begin{array}{l}0.01 \\
0.05 \\
30 \\
200\end{array}$ & $\begin{array}{l}2-4 \\
\text { months* }\end{array}$ \\
\hline ABA & $\begin{array}{l}\text { Embryo } \\
\text { maturation }\end{array}$ & $\begin{array}{l}\text { LS, sucrose, } \mathrm{pH} \\
5.7-5.8\end{array}$ & $\begin{array}{l}\text { Abscisic } \\
\text { acid** } \\
\text { Cefotaxime } \\
\text { Zeatin riboside }\end{array}$ & $\begin{array}{l}1 \\
200 \\
0.2\end{array}$ & $1-2$ months \\
\hline F9 & $\begin{array}{l}\text { Shoot } \\
\text { induction }\end{array}$ & LS, sucrose, $\mathrm{pH}$ 5.7-5.8 & $\begin{array}{l}\text { Cefotaxime Zeatin } \\
\text { riboside }\end{array}$ & $\begin{array}{l}200 \\
0.2\end{array}$ & $\begin{array}{l}\text { until shoots } \\
\text { form }\end{array}$ \\
\hline
\end{tabular}

\section{Selection and regeneration}

After the 3 days of co-cultivation, the infected explants were cleansed adequately with antibiotic wash solution. The explants were then dubbed on sterile filter papers and positioned on F15 media supplemented with $30 \mathrm{~g} / \mathrm{L}$ mannose and $250 \mathrm{~m} \mathrm{~g} / \mathrm{L}$ cefotaxime for callus induction for 3 days then transfer to $\mathrm{F} 9$ media for callus proliferation for 28 days. The explants were displaced on fresh F9 media once after every two weeks (Kreuze et al. 2008). The resultant embryogenic calli surviving the selection pressure were displaced to G24D media for embryo development and initiation of shoots. At this stage, not all calli were displaced to G24D medium, the calli were subdivided and some put on F25 medium. This followed a preliminary observation of root emergence before shoot regeneration on G24D medium. Fully developed shoots were multiplied on hormone-free sweet potato propagation media before they were displaced to peat moss for hardening.

\section{Molecular analysis of transgenic plants}

The presumed transgenic plants were screened for the presence of IPT genes using PCR with gene-specific primers. With a modified cetyltrimethylammonium bromide (CTAB) method as described by Zidani et al. (2005), the genomic DNA was extracted from the leaf tissues of presumed transgenic as well as the nontransgenic (control) plants.

\section{DNA extraction from presumed transgenic plants}

About $3 \mathrm{~g}$ of freshly freeze-dried leaf tissues from the presumed transgenic plants were crushed using a pestle and mortar and $9 \mathrm{~mL}$ of CTAB extraction buffer $(100 \mathrm{mM}$ Tris$\mathrm{HCL}, 1.4 \mathrm{M} \mathrm{NaCl}, 20 \mathrm{mM}$ EDTA) at $65^{\circ} \mathrm{C}$. The liquid mixture was displaced to a $50 \mathrm{~mL}$ falcon tube and incubated at $65^{\circ} \mathrm{C}$ in a water bath for $30 \mathrm{~min}$. Four $\mathrm{mL}$ of chloroform isoamyl alcohol (24: 1) was added to the samples and inverted twice to mix. The mixture was centrifuged at $5500 \mathrm{rpm}$ for $10 \mathrm{~min}$ and after that $1 \mathrm{~mL}$ of the aqueous layer was carefully displaced to $2 \mathrm{~mL}$ Eppendorf tube. To precipitate DNA, $0.7 \mathrm{~mL}$ of isopropanol (stored at $-20^{\circ} \mathrm{C}$ ) was added to each sample and inverted twice to mix. The tubes were chilled at $-20^{\circ} \mathrm{C}$ for $20 \mathrm{~min}$ and then centrifuged at $5500 \mathrm{rpm}$ for $15 \mathrm{~min}$. The supernatant was discarded, and $1 \mathrm{~mL}$ of $70 \% \mathrm{v} / \mathrm{v}$ ethanol was added to cleanse the DNA pellet and centrifuged at $12000 \mathrm{rpm}$. The supernatant was discarded, and the pure DNA pellet air dried for $30 \mathrm{~min}$, resuspended in $100 \mu \mathrm{l}$ of sterile water and stored at $-20^{\circ} \mathrm{C}$.

\section{DNA quantity estimation through gel electrophoresis}

The concentration of the isolated plant genomic DNA was estimated by running on $0.8 \%(\mathrm{w} / \mathrm{v})$ agarose gel where $5 \mu \mathrm{L}$ of the genomic DNA was mixed with $1 \mu \mathrm{L}$ of 6 times loading dye (New England Biolabs, Ipswich, USA) and 1 $\mu \mathrm{L}$ of sybr green (Invitrogen, USA) before loading for electrophoresis against $5 \mu \mathrm{L}$ of $1 \mathrm{~kb}$ ladder (New England Biolabs) and run at 100 volts for 30 min using 1 time TAE buffer. The level fluorescence of the sample DNA bands 
against the $1 \mathrm{~kb}$ ladder was used to determine the amount of the DNA when visualized using gel documentation equipment and recording the gel.

\section{Polymerase Chain Reaction assay}

The PCR fragment containing the coding regions of IPT gene was amplified using its gene-specific primer. Forward primer; 5'-CCAACTTGCACAGGAAAGAC and Reverse primer; 5'-CTAATACATTCCGAACGGATGAC. The results of the PCR were determined through agarose gel electrophoresis where $5 \mu \mathrm{L}$ of the DNA was mixed with 1 $\mu \mathrm{L}$ of 6 times gel loading dye (New England Biolabs, Ipswich, USA) and $1 \mu \mathrm{L}$ of sybr green gel loading dye (Invitrogen, USA) before loading. Electrophoresis was done at 100 volts for $40 \mathrm{~min}$ using $0.8 \% \mathrm{w} / \mathrm{v}$ agarose in 1 times TAE buffer and $1 \mathrm{~kb}$ ladder (New England Biolabs) as the standard. Gel documentation equipment was used to visualize and record the gel.

\section{Experimental set up for drought stress of sweet potato plants}

Pot experiments were performed to evaluate the drought stress of transgenic sweet potatoes and non-transgenic sweet potatoes. The experiments were conducted in a greenhouse at the Kenyatta University plant transformation laboratory. Vine cuttings of about $4 \mathrm{~cm}$ were obtained and planted in $30 \mathrm{~cm}$ plastic pots containing $15 \mathrm{~kg}$ of homogeneous soil which were completely air dried with 1 plant per pot. All plants were watered sufficiently every two days and allowed to grow for 4 weeks before they experienced drought stress experiments. Plants at the same stage of development and the same size were then faced with drought stress for 96 days by withholding irrigation. Treatments were a combination of three irrigation regimes; severe drought stress (water withheld) moderate drought stress (irrigated $50 \%$ every 2 days) and control (irrigated $80 \%$ every 2 days) for both transgenic and non-transgenic. Rewatering was conducted at the end of the growth phase, after every two days until the plant fully recovered. Treatments were arranged in a completely random design with 3 replicates of 4 pots per treatment. This was performed according to the protocol by Saraswati et al. (2012).

\section{Measurement of physiological and morphological characteristics}

Data on physiological and morphological characteristics (relative water content, chlorophyll content and growth parameters) were collected from mature, healthy, and fully expanded third, fourth and fifth leaves of 96-day old plants at day 42, 63 and 96 and on the 1st, 5th, and 9th day of recovery. Sampling of control, stressed and recovered plants was done simultaneously.

\section{Leaf relative water content}

To minimize the age effects, the leaves were collected from the mid-section of the vine. It is used to monitor the relative water content. Individual leaves were first removed from the stem and then weighed to obtain the fresh weight (FW). After fresh weight determination, leaves were floated in distilled water for $24 \mathrm{~h}$ obtaining the turbidity weight (TW). Dry weight (DW) of leaves was determined by oven-drying the leaves at $80^{\circ} \mathrm{C}$ for $72 \mathrm{~h}$ and then the weight was determined. All mass measurements were taken using an analytical scale with precision of $0.0001 \mathrm{~g}$. Values of FW, TW, and DW were used to count the leaf relative water content (RWC) using the formula:

$$
\text { RWC }(\%)=[(\text { FW-DW }) /(\text { TW-DW })] * 100
$$

\section{Leaf chlorophyll concentration}

Three plants per replicate were used for chlorophyll determination. Ten fresh leaf discs from the third fully expanded leaf were sampled, chlorophyll was extracted using $100 \% \mathrm{v} / \mathrm{v}$ acetone by crashing the leaves using a mortar and pestle. The chlorophyll was obtained from the leaf debris by centrifugation at 5000rpm for 10 minutes and the supernatant was pipetted and displaced into clean $2 \mathrm{~mL}$ Eppendorf tubes. The chlorophyll concentration was measured using a spectrophotometer at 662, 645 and 470 $\mathrm{nm}$ wavelengths and the readings at these absorbance levels were used to count chlorophyll a, chlorophyll b and carotenoid concentration. Measurements and calculations were performed according to Lichtenthaler (1987).

\section{Chl a $=11.75 \mathrm{~A} 662-2.350 \mathrm{~A} 645 \mathrm{Chl} \mathrm{b}=18.61 \mathrm{~A} 645-$ 3.960A662}

$$
\mathrm{C} \mathrm{x}+\mathrm{c}=1000 \mathrm{~A} 470-2.27 \mathrm{Ca}-81.4 \mathrm{Cb} / 227
$$

\section{Plant growth parameters}

Vine length, internode length, branch number, leaves per vine, leaf width and leaf length were measured on 4 randomly sampled plants per treatment a week before stress treatment, at 42, 63 and 96 days after planting (DAP). The increment in each of these traits was determined by the difference between the measurements at 96 DAP and 42 DAP, stated as a percentage.

\section{Data analysis}

Transformation frequency, transformation efficiency and regeneration frequency differences between genotypes were analyzed using ANOVA at $95 \%$ confidence interval. Transformation efficiency (TE) was counted as affirmed presumed transformants divided by the number of initially infected explants stated as percentage whereas the transformation frequency (TF) was determined by dividing the number of presumed transformed callus by the number of infected explants stated as a percentage. Regeneration frequency was counted as the number of shoots formed over the number of explants used stated as percentage. On drought stress experiments, experiments on growth parameters (leaf length, width, internode length, vine length, leaves per vine and number of branches per plant) and relative water content were conducted in a completely randomized fashion and data collected analyzed with statistical analysis system (SAS). Treatment means were compared using Turkey's tests at the 5\% level of significance. 


\section{RESULTS AND DISCUSSION}

\section{In-vitro response of sweet potato to tissue culture}

Explants from three sweet potato varieties (Kemb36, KSP36 and Jewell) produced shoots within 10 days of culture. Kemb36 explants were the first to shoot in 4 days while KSP36 and Jewell explants took 5 and 7 days, respectively to shoot (Figure 4). These sweet potato varieties were cultured and maintained under in-vitro conditions devoid of any contamination.

\section{Callus induction}

Plant explants from all the sweet potato cultivars induced embryogenic and/or non-embryogenic callus. Callus formation started 3 weeks after incubating the explants on F9 callus induction medium. Several calli formed on the leaf lamina and petiole of the explants (Figure 5.A), but only those emerging from the base of the petiole survived repeated subculture and formed embryogenic callus (Figure 5.B) on selective medium supplemented with $30 \mathrm{~g} / \mathrm{L}$ mannose.

\section{Optimization of mannose concentration for selection of transformants}

The PNOV-IPT gene constructs harbored the PMI gene as a selectable marker gene which was used to select for putatively transformed calli and plantlets. An experiment to establish the optimum mannose concentration to be used in selection of transformed callus/cells was conducted at varying levels of mannose $(0,10,20,30$, and 40) (Figure 6.) using leaf and stem explants in 3 replications. After 6 weeks on selection media, it was observed that a concentration of $30 \mathrm{~g} / \mathrm{L}$ of mannose was optimum to select for transformed calli (Figure 7.A). The non-transformed explants began to turn brown on the selection media and gradually died on the medium. Moreover, all the calli died on the medium with mannose above $30 \mathrm{~g} / \mathrm{L}(40 \mathrm{~g} / \mathrm{L})$ (Figure 7.C). However, the number of calli surviving on 30 $\mathrm{g} / \mathrm{L}$ mannose concentration was remarkably high (Figure 7.D).

\section{Regeneration of embryogenic calli into plantlets}

Green calli were harvested after 8 weeks of growth on F9 medium and displaced to G24D embryo induction medium for somatic embryogenesis (Figure 8.A). Embryogenic structures formed on G24D after 1 month, and were displaced to F25 embryo maturation medium. The mature embryos appeared after 1 month on F25 and were displaced to hormone-free F9 medium to allow development into shoot. At this stage, it was observed that most embryogenic calli that did not form shoots just proliferated in roots (Figure 8.B). The shooting process began with the formation of dome-shaped structures that later formed primordial leaves (Figure 8.C). The primordial leaves further grew to form shoots and whole leaves (Figure 8.D). The first fully developed plants were obtained after about 4 months from the beginning of the transformation experiment. However, more plants continued to form until end of the 8th month. In all experiments performed (approximately 120 explants each), only 14 and 8 independent events were regenerated for Jewel (non-African cultivar) and kemb36 varieties respectively. Though KSP36 variety performed well during callus induction and embryo formation, the variety just proliferated into roots on the G24D media but did not give any plant.

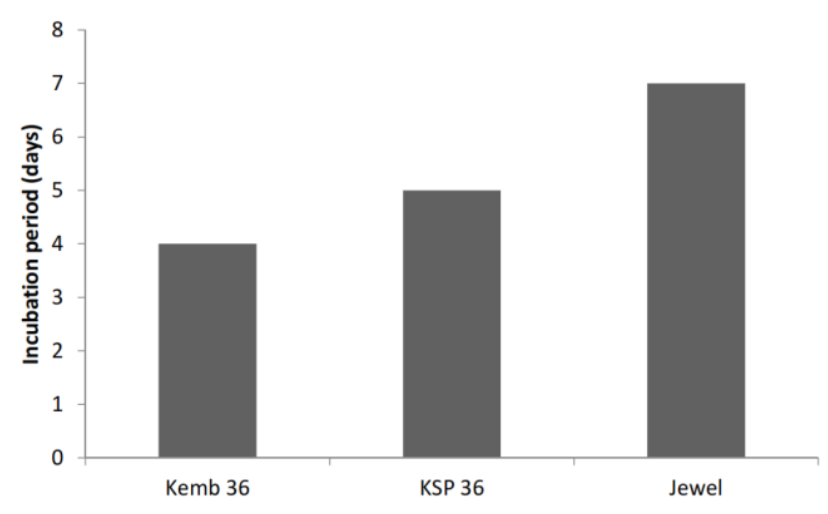

Figure 4. In-vitro micro-propagation of sweet potato. Number of days taken for shoots to emerge in-vitro from stem nodes of 3 sweet potato varieties after initiation in tissue culture.

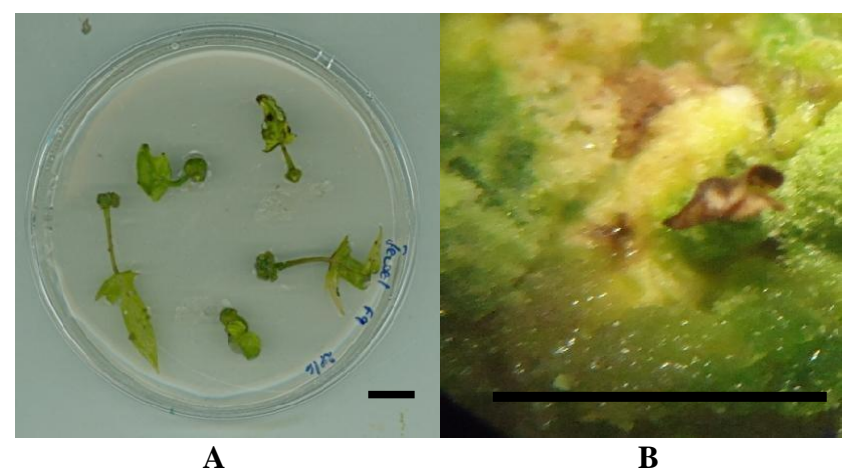

Figure 5. Callus proliferation on callus induction medium. A. Whole leaf explants form calli at the base of the leaf petiole. B. Callus proliferation after excising it from the base of the leaf petiole $(\mathrm{Bar}=2 \mathrm{~cm})$.

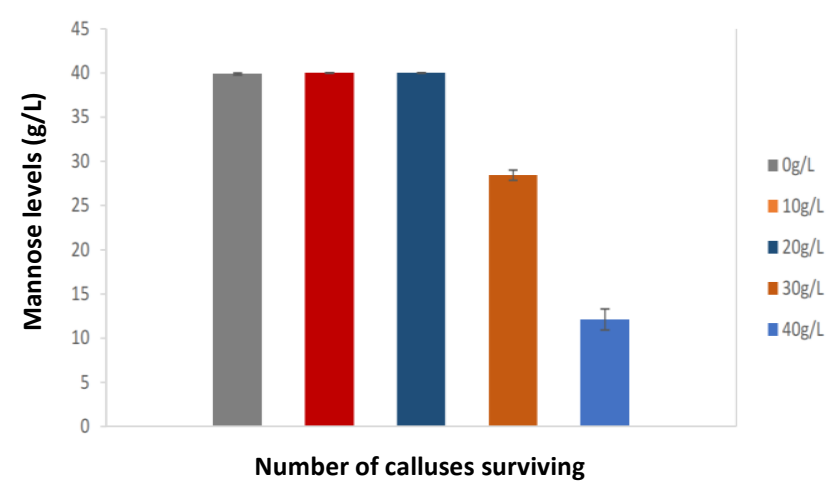

Figure 6. Effect of mannose concentration on the survival of the sweet potato calli. The concentration of $20 \mathrm{~g} / \mathrm{L}$ and below did not have any effect on callus proliferation. Calli on the concentration above $30 \mathrm{~g} / \mathrm{L}$ registered massive deaths thus a concentration of 30 $\mathrm{g} / \mathrm{L}$ selected to the optimal selection pressure. 


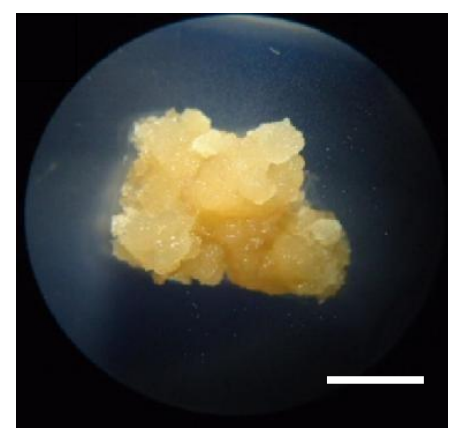

A

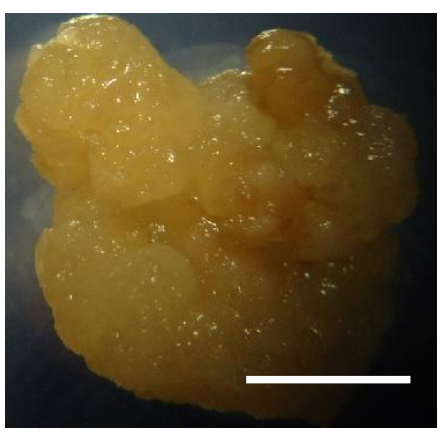

$\mathbf{B}$

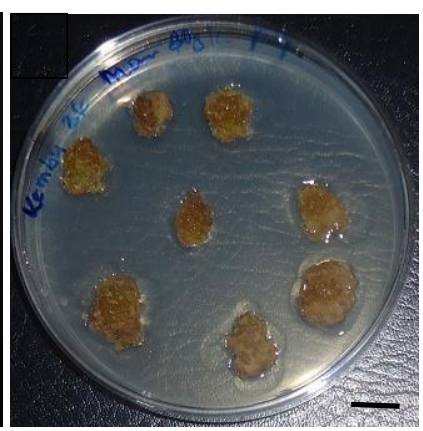

C

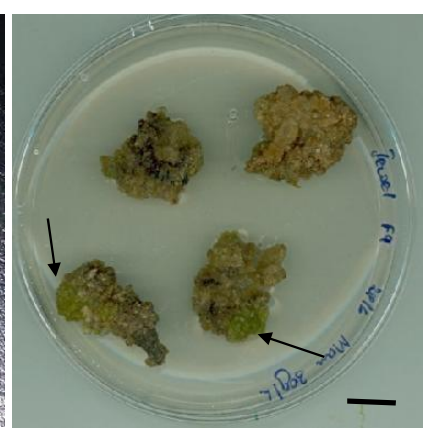

D

Figure 7. Stages of callus development on selection media containing mannose. A. Well-established callus 4 weeks on callus induction media. B. Kemb36 callus during early stage of embryogenesis (note the browning of the callus caused by mannose pressure). C. Callus greatly reduced 10 wks on selection media containing $40 \mathrm{~g} / \mathrm{L}$ of mannose. D. Jewel callus succumb to mannose pressure 12 wks on selection media (arrows show the transformed portion of the calli) $(\mathrm{Bar}=1 \mathrm{~cm})$.

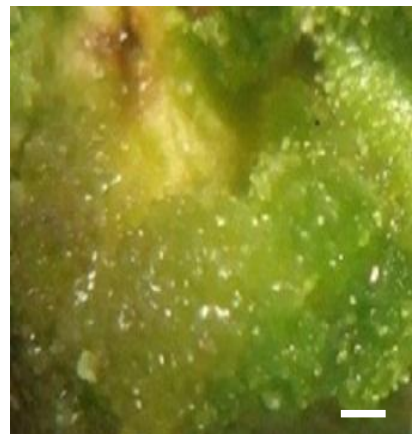

A

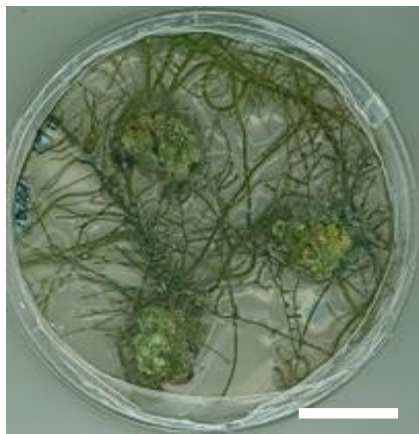

$\mathbf{B}$

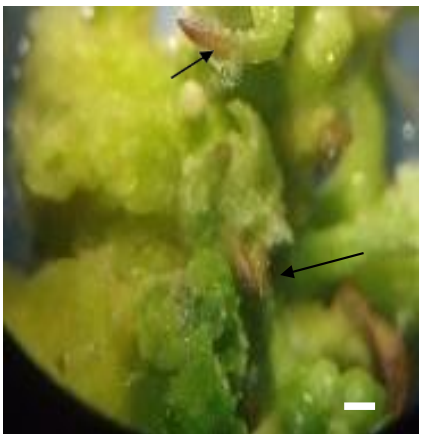

$\mathbf{C}$

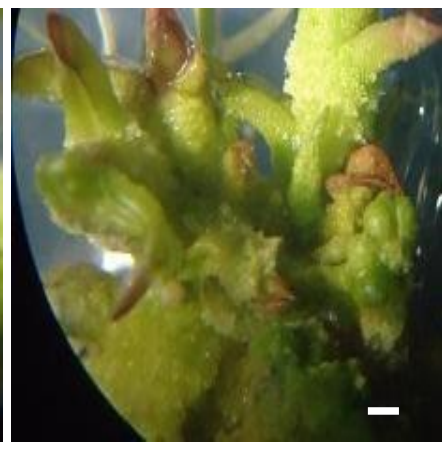

D

Figure 8. Stages of sweet potato regeneration from embryogenic calli. A. Calli at early stages of embryogenesis $(B a r=0.1 \mathrm{~cm}) . \mathrm{B}$. Proliferation of roots on G24D medium $(B a r=1 \mathrm{~cm})$. C. Onset of primordial leaf formation $($ Bar $=0.1 \mathrm{~cm})$. (The arrows show the young leaf primordia). D. Embryogenic calli forming shoots after incubation on regeneration medium $($ Bar $=1 \mathrm{~cm})$.

\section{Hardening and acclimatization of presumed transgenic plants}

Fully developed presumed transgenic plants (Figure 9.A) were displaced to autoclaved peat moss in small pots for hardening and acclimatization. The plants were first carefully removed from the culture media to avoid breaking the roots. The roots were cleansed with sterile water to remove any media remnant attached and subsequently displaced to peat moss. The pots were covered by polythene bags for 3 days to avoid excessive evapotranspiration (Figure 9.B). Three days later, the polythene bags were removed (Figure 9.C), then plants were displaced to larger pots with normal soil (Figure 9.D) where they grew vigorously.

Molecular analysis of presumed transgenic sweet potato Genomic DNA was extracted from presumed sweet potato leaves and quantified by running on an agarose gel (Figure 10). The good quality DNA with high concentration was further used for molecular analysis. PCR analysis was carried out using IPT gene specific primers on the regenerated plant to determine the presence of $I P T$ gene and 5 out of 7 plants tested were positive (Figure 11). Even though stems explants regenerated into plants, it was interesting to note that only 2 of these regenerated plants were PCR positive.

\section{Response of the sweet potato varieties to transformation and regeneration}

To evaluate the response of the varieties on transformation, the leaf and stem explants from the three varieties were tested for their response to selection pressure (Table 2). There was a significant difference observed in transformation frequency among the three sweet potato varieties at $95 \%$ confidence interval using one-way ANOVA. However, although mannose tolerant calli were observed in all three varieties, only explants from two varieties Kemb36 and Jewel gave putatively transgenic plants. Of the two explants analyzed, the leaf explant responded better to transformation and regeneration (Table 3).

The values shown are means and standard errors of transformation frequencies (TF), regeneration frequencies (RF), regeneration efficiencies (RE), transformation 
efficiencies (TE), and embryogenic calli formation of the three selected sweet potato varieties. Figures with the same letter in the same column are not significantly different. (0.000-implies no plant regenerated).

The data shows how the two explants responded to transformation and regeneration. The values are means and standard errors. Different letters in the same column mean there is significant difference between the 2 explants in terms of response to transformation and regeneration.

\section{Plant growth response to drought stress}

Under well-watered conditions, before water stress treatment, both transgenic and wild-type plants did not show any visible difference in growth. All the plants grew vigorously with a lush green color (Figure 12).

After 14 days of drought stress, the wild type started to wilt, and leaves drooped while the transgenic plants showed normal growth. After 63 DAP and as drought stress becomes more severe, senescence began to be manifest in the leaves which wilted, turned yellow then brown before finally falling off the plant. Compared to the transgenic plants, (Figure 13.A) senescence was more pronounced in wild-type (Figure 13.B) than the transgenic. During rewatering, the transgenic plants (Figure 13.C) recovered much earlier compared to wild-type (Figure 13.D) that remained chlorotic even after 9 days of rewatering.

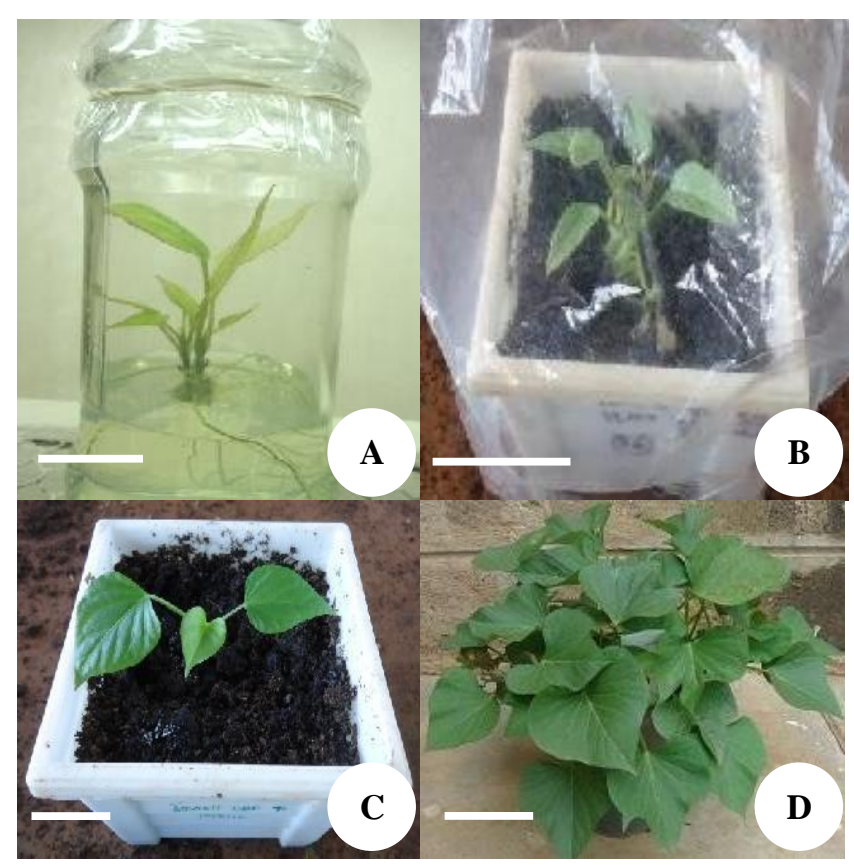

Figure 9. Hardening and acclimatization of presumed transgenic plants. A. Putative regenerant from embryogenic call. B. Jewel cultivar shoots after transfer from the medium. C. Regenerated plant during hardening. D. Completely grown and established plant in the soil.

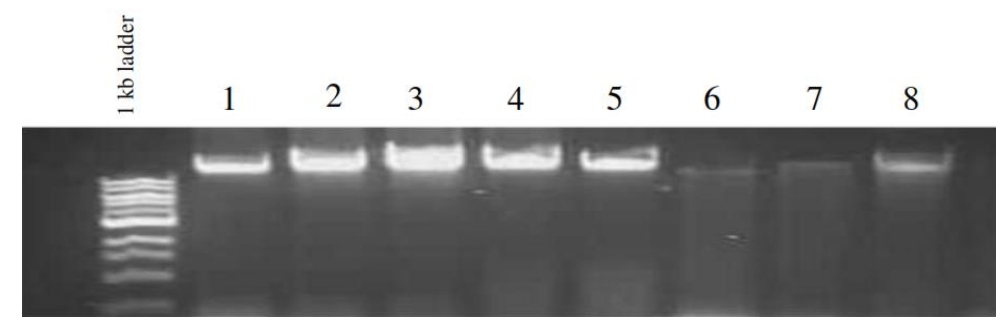

Figure 10. Gel electrophoresis showing purified genomic DNA from pSARK IPT sweet potato plants. Lane 1-6; DNA from the Jewel sweet potato variety. Lane 7-8; DNA from Kemb36 sweet potato variety.

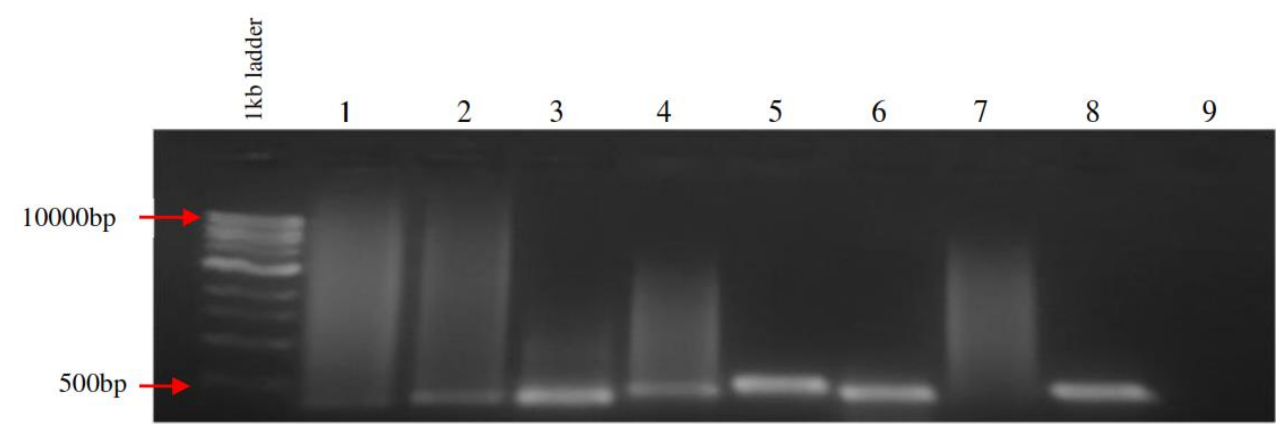

Figure 11. PCR analysis of T0 plants using IPT gene-specific primers on sweet potato genomic DNA. Lanes 1 and 2; presumed transgenic Kemb36. Lanes 3-7; presumed transgenic Jewel. Lane 8; +ve control (PNOV-IPT plasmid), Lane 9;-ve control. 
Table 2. Transformation frequency, regeneration frequency, transformation efficiency and regeneration efficiency of 3 sweet potato varieties transformed using pSARK-IPT gene.

\begin{tabular}{lccccc}
\hline Variety & $\begin{array}{c}\text { Means of embryogenic } \\
\text { calli }\end{array}$ & $\begin{array}{c}\text { Means of TF } \\
(\boldsymbol{\%})\end{array}$ & $\begin{array}{c}\text { Means of RF } \\
(\boldsymbol{\%})\end{array}$ & $\begin{array}{c}\text { Means of TE } \\
(\boldsymbol{\%})\end{array}$ & $\begin{array}{c}\text { Means of RE } \\
(\boldsymbol{\%})\end{array}$ \\
\hline KSP36 & $17.667 \pm 1.745 \mathrm{a}$ & $44.167 \pm 4.362 \mathrm{a}$ & $0.000 \pm 0.000$ & $0.000 \pm 0.000$ & $0.000 \pm 0.000$ \\
Kemb36 & $20.000 \pm 2.251 \mathrm{ab}$ & $50.000 \pm 5.627 \mathrm{ab}$ & $0.833 \pm 0.833 \mathrm{a}$ & $0.8330 .833 \mathrm{a}$ & $5.522 \pm 2.162 \mathrm{a}$ \\
Jewell & $22.833 \pm 0.946 \mathrm{~b}$ & $57.083 \pm 2.364 \mathrm{~b}$ & $2.083 \pm 1.193 \mathrm{a}$ & $2.083 \pm 1.193 \mathrm{a}$ & $12.808 \pm 2.748 \mathrm{a}$ \\
LSD $(\mathrm{P}>0.05)$ & 5.071 & 12.678 & 2.755 & 2.755 & 7.111 \\
\hline
\end{tabular}

Table 3. The overall effect of explants used on transformation frequency (TF), regeneration frequency (RF), and regeneration efficiency (RE).

\begin{tabular}{lccccc}
\hline \multicolumn{1}{c}{ Explant } & $\begin{array}{c}\text { Means of embryogenic } \\
\text { calli }\end{array}$ & $\begin{array}{c}\text { Means of TF } \\
(\boldsymbol{\%})\end{array}$ & $\begin{array}{c}\text { Means of RF } \\
(\boldsymbol{\%})\end{array}$ & $\begin{array}{c}\text { Means of TE } \\
(\boldsymbol{\%})\end{array}$ & $\begin{array}{c}\text { Means of RE } \\
(\boldsymbol{\%})\end{array}$ \\
\hline Leaf & $22.67 \pm 3.393 \mathrm{a}$ & $56.667 \pm 8.483 \mathrm{a}$ & $1.944 \pm 1.843 \mathrm{a}$ & $1.944 \pm 1.843 \mathrm{a}$ & $7.884 \pm 4.758 \mathrm{a}$ \\
Stem & $17.667 \pm 3.393 \mathrm{~b}$ & $44.167 \pm 8.483 \mathrm{~b}$ & $0.000 \pm 1.843 \mathrm{~b}$ & $0.000 \pm 1.843 \mathrm{~b}$ & $4.336 \pm 4.758 \mathrm{~b}$ \\
LSD $(\mathrm{p}>0.05)$ & 3.393 & 8.483 & 1.843 & 1.843 & 4.758 \\
\hline
\end{tabular}

Table 4. Effect of moderate and severe drought stress on the morphological characteristics of transgenic $(\mathrm{T})$ and non-transgenic $(\mathrm{N})$ sweet potato.

\begin{tabular}{lcccccc}
\hline & \multicolumn{7}{c}{ Treatment } \\
\cline { 2 - 7 } Parameters & TC & NC & TM & NM & TS & NS \\
\hline Vine Length & $28.700 \pm 0.404 \mathrm{a}$ & $28.533 \pm 0.291 \mathrm{a}$ & $28.900 \pm 0.586 \mathrm{a}$ & $17.667 \pm 0.657 \mathrm{c}$ & $21.667 \pm 0.267 \mathrm{~b}$ & $12.956 \pm 0.267 \mathrm{~d}$ \\
Internode Length & $1.133 \pm 0.067 \mathrm{a}$ & $1.100 \pm 0.058 \mathrm{a}$ & $1.133 \pm 0.067 \mathrm{a}$ & $0.867 \pm 0.033 \mathrm{ab}$ & $0.967 \pm 0.088 \mathrm{a}$ & $0.607 \pm 0.007 \mathrm{~b}$ \\
Branches/Vine & $2.667 \pm 0.333 \mathrm{~b}$ & $3.333 \pm 0.333 \mathrm{ab}$ & $5.000 \pm 0.577 \mathrm{a}$ & $2.000 \pm 0.577 \mathrm{bc}$ & $2.667 \pm 0.333 \mathrm{~b}$ & $0.333 \pm 0.333 \mathrm{c}$ \\
leaf Area & $80.400 \pm 0.300 \mathrm{a}$ & $79.223 \pm 1.772 \mathrm{ab}$ & $75.403 \pm 1.043 \mathrm{~b}$ & $41.823 \pm 0.939 \mathrm{~d}$ & $49.300 \pm 0.681 \mathrm{c}$ & $24.833 \pm 0.601 \mathrm{e}$ \\
No. Leaves/Vine & $40.000 \pm 1.155 \mathrm{a}$ & $39.000 \pm 2.082 \mathrm{a}$ & $34.667 \pm 0.882 \mathrm{a}$ & $22.000 \pm 1.155 \mathrm{~b}$ & $21.333 \pm 0.882 \mathrm{~b}$ & $15.333 \pm 0.667 \mathrm{c}$ \\
\hline
\end{tabular}

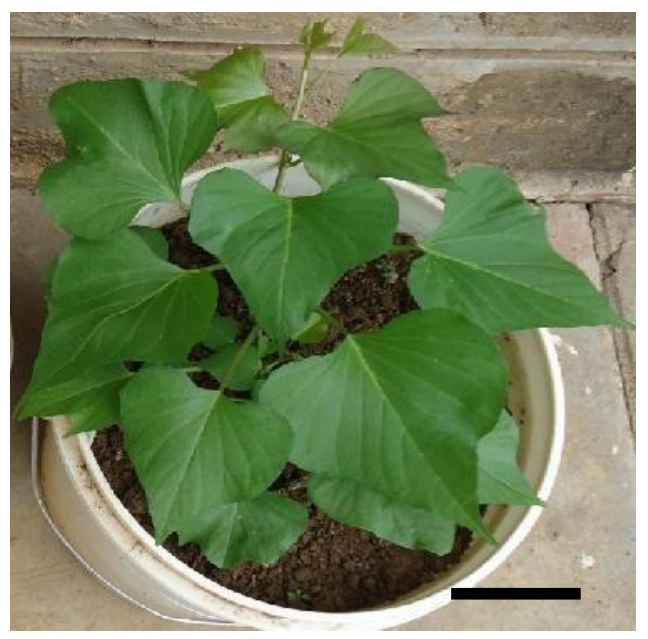

Figure 12. Morphological appearance of the plants a day before the onset of stress experiment. 28 days after planting (DAP) (Bar= $4 \mathrm{~cm})$.

Effect of drought stress on vine length, internode length and number of branches

Plants responded differently to different drought stress treatments. Moderate drought stress relatively increased branching in transgenic stressed plants compared to non- transgenic stressed plants (Table 4). However, both transgenic stressed and non-transgenic stressed plants were heavily affected by severe drought stress. Compared to the controls (C), moderate drought stress decreased both vine length and the internode length in transgenic stressed and non-transgenic plants. The average vine length and internode length reduction $(\mathrm{P}<0.05)$ in transgenic stressed was $21.67 \mathrm{~cm}$ and $0.97 \mathrm{~cm}$ respectively and corresponding decrease in wild-type was $12.27 \mathrm{~cm}$ and $0.61 \mathrm{~cm}$. As the days progressed and drought intensity increased, both transgenic plants and non-transgenic (wild types) showed a further decrease in both vine length and internode length, but this was more severe in wild types (Table 4).

\section{Effect of drought stress on leaf area and number of leaves per vine}

Under well-watered conditions, both transgenic and wild-type plants showed no significant difference in leaf area and number of leaves per vine (Table 4). However, further drought stress had a great effect on both leaf area and number of leaves per vine. Compared to the control, the transgenic plants showed a higher leaf area $(\mathrm{P}<0.05)$ and leaves per vine under severe stress of $71.17 \mathrm{~cm} 2$ and $21.33 \mathrm{~cm}$ respectively. The corresponding leaf area and number of leaves per vine in wild-type were $24.83 \mathrm{~cm} 2$ and $15.33 \mathrm{~cm}$ respectively. 


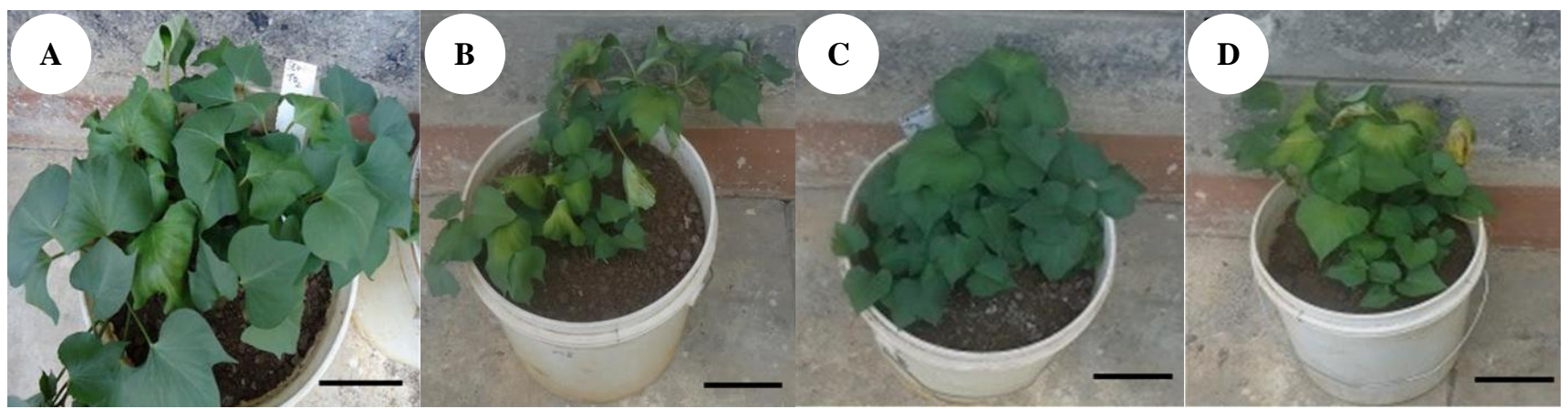

Figure 13. Effect of drought stress on transgenic and wild-type sweet potato growth. A. Transgenic Jewel variety 35 days (63 DAP) after onset stress treatment. B. Wild-type Jewell variety 35 days (63 DAP) after the start of stress treatment. C. Transgenic plant at 9 days after rewatering. D. Wild-type plant 9 days after rewatering $(\mathrm{Bar}=4 \mathrm{~cm})$.

Values are means and SE of three replicates collected at day 63 after induction of drought stress. Means with the same letters in a raw are not significantly different. Plants under well-watered conditions served as control. TCtransgenic control; NC-non transgenic control; TMtransgenic moderately stressed; NM-non transgenic moderately stressed; TS-transgenic severe stressed; NS-non transgenic severe stressed.

Changes in leaf relative water content under drought stress and re-watering conditions

The relative water content (RWC) was measured one day before drought stress, on day 21 and 63 after imposing drought and then finally on the $1^{\text {st }}, 5^{\text {th }}$, and 9 th day after rewatering. Two weeks after withholding water, there was a significant decrease in the leaf RWC of both transgenic and wild-type plants. The reduction was more profound under severe drought stress conditions. Compared to the wild type, the transgenic plants registered a higher RWC under both moderate (Figure 14.) and severe drought stress (Figure 15.) than their wild-type counterparts.

Re-watering had a great effect on RWC after drought stress. In overall, the transgenic stressed plants showed better recovery than the wild type in that they recovered faster compared to wild-type. However, neither of the plants recovered fully from severe drought stress.

\section{Effect of drought stress on total leaf chlorophyll content}

Under sufficient water treatment, both transgenic and wild-type had similar total chlorophyll content. However, there was a significant reduction in total chlorophyll content 21 days after imposing drought stress. The total decrease in transgenic plants was $36.9 \%$ and $27.7 \%$ under moderate and severe stress respectively. The corresponding decrease in wild-type was $27.3 \%$ and $23.0 \%$ under similar conditions. As the drought treatment progressed both transgenic and wild-type plants showed a further reduction in the total chlorophyll content, but this was more severe in wild types.

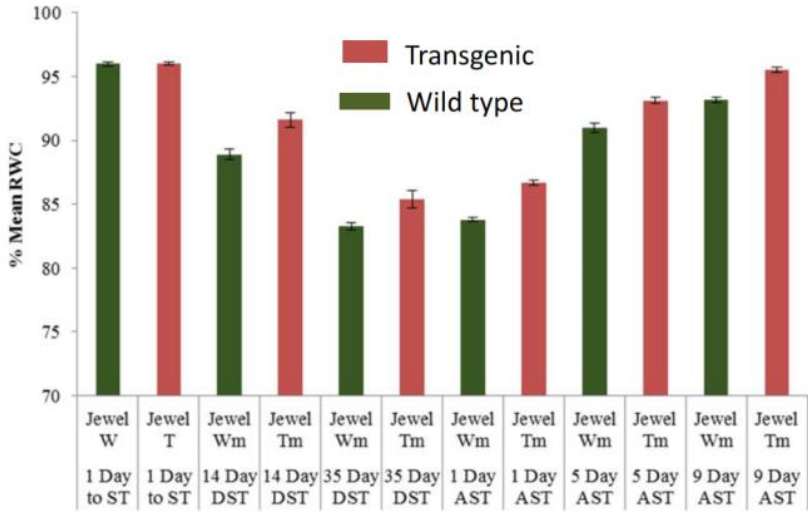

Figure 14. Relative water content in wild-type (W) and transgenic (T) sweet potato during moderate drought stress and recovery. Wwild type; T-transgenic; WM-wild type under moderate stress; TM-transgenic under moderate stress; ST-stress treatment; DSTduring stress treatment; AST-after stress treatment.

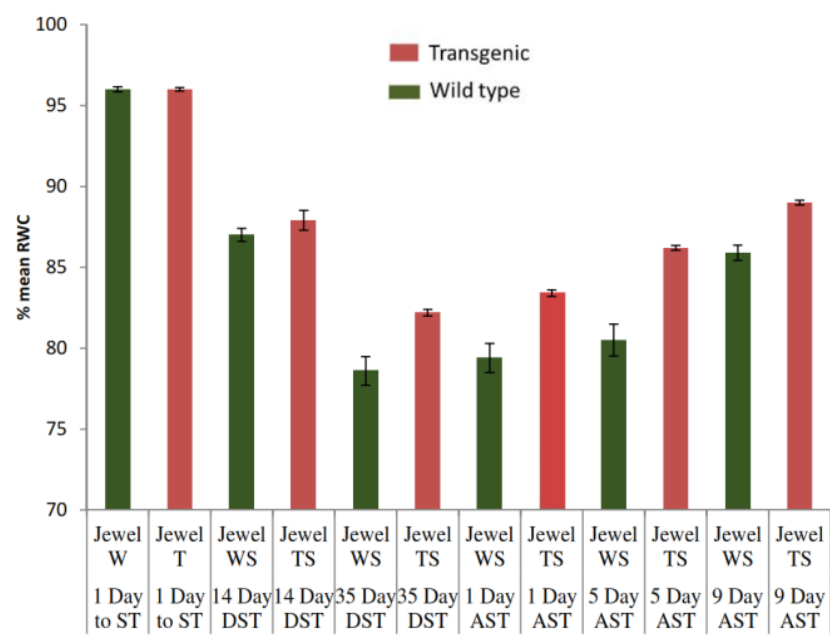

Figure 15. Relative water content of wild-type (W) and transgenic $(\mathrm{T})$ sweet potato during severe drought stress $(\mathrm{S})$ and recovery. W-wild type; T-transgenic; WS-wild type severe stressed; TS-transgenic severe stressed; ST-stress treatment; DSTduring stress treatment; AST-After stress treatment. 

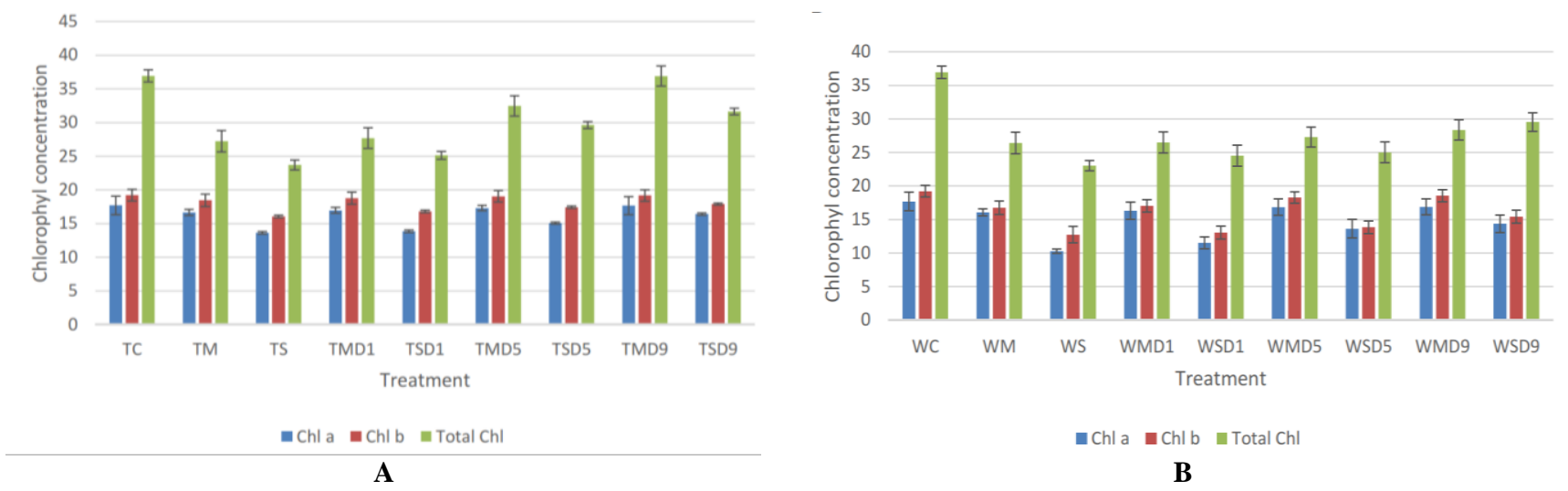

Figure 16. Effect of drought stress on total chlorophyll content. A. Chlorophyll content of Jewell transgenic variety under moderate and severe drought stress. B. Chlorophyll content of the Jewell wild type variety under moderate and severe drought stress.

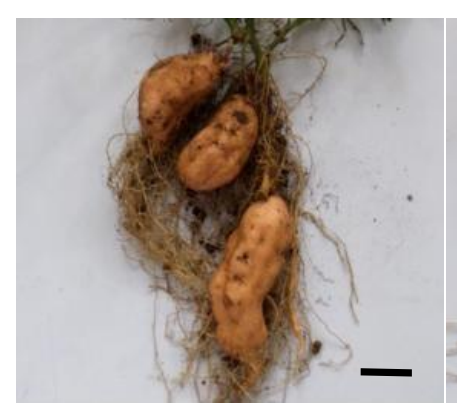

A

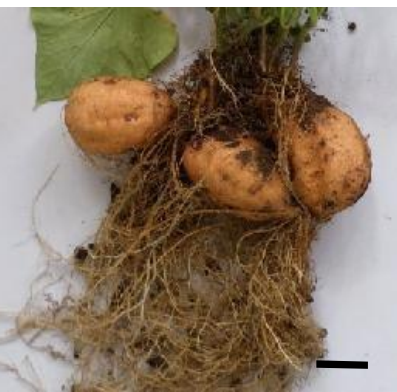

B

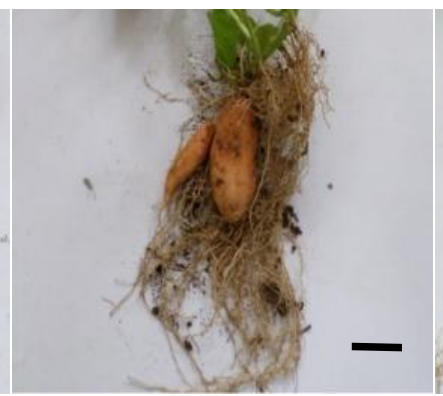

C

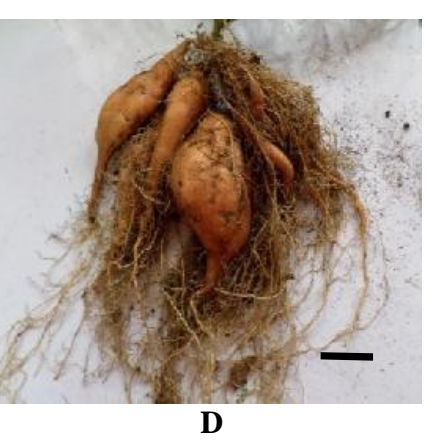

D

Figure 17. The effect of drought stress on visual rating of plants growth and storage root formation in transgenic pSARK-IPT and the non-transgenic sweet potatoes. A. Non-transgenic tuber formation under control conditions. B. Transgenic pSARK-IPT tuber formed under control condition. C. Non-transgenic tuber formed under severe drought stress. D. pSARK-IPT tuber formed under severe drought stress.

Upon re-watering, the moderately stressed plants recorded a drastic increase in total chlorophyll content within the first 3 days then gradually till they reached the control level after 9 days (Figure 16.). On the other hand, chlorophyll content of severe stressed transgenic plants increased slowly within the first 3 days then rapidly, whereas the severe stressed wild type did not show signs of recovery even after 9 days.

\section{Effect of drought stress on tuber and root formation}

Under normal conditions, there was no phenotypic difference in the tuber formation between the wild-type (Figure 17.A) and the pSARK-IPT transgenic plants (Figure 17.B). However, under reduced irrigation the wildtype plants were greatly affected by drought stress and hence a serious impact on tuber formation (Figure 17.C). The transgenic plants, on the other hand, had visibly bigger and more tubers (Figure 17.D) compared to the wild type under the same conditions.

\section{Discussion}

Sweet potato transformation and regeneration

Through the Agrobacterium-mediated gene transfer method, the conversion of two varieties of transgenic sweet potatoes was successful. In the test of transformability and regeneration ability, two varieties, namely Jewel (nonAfrican varieties) and Kemb36, produced transgenic plants, whereas one variety (KSP36) regenerated no plant, even though this variety performed well during callus formation after transformation. This is consistent with the findings by Mervat et al. (2009) who established that different cultivars show a different response to in-vitro regeneration. In the invitro regeneration process, growth regulators as parameters play an important role. A balance between the auxins and cytokinin, therefore, is important for conversion of somatic embryos into shoots (Santa Maria et al. 2009). In this study, this regeneration variation among genotypes could be attributed to significant variability in genotype response to growth regulator combination and genotype dependency to in-vitro regeneration. 
In this study, for introduction of pSARK-IPT genes into sweet potato cells which later tolerate drought in transgenic events, Agrobacterium tumefaciens was used. Meanwhile, regeneration method in this study used somatic embryogenesis method because it produced high-frequency selection during transformation since each plant comes from a single modified cell (Sefasi et al., 2012). Two major factors were studied for their effect on transformation, embryogenic callus formation and hence regeneration of selected sweet potato varieties. This included the type of explants and the type of variety used.

To understand their effect on transformation, embryogenic callus formation and regeneration, leaf and stem explants were compared. Although the type of explants used did not affect the frequency of the total callus formed, the type of explants had a significant effect on the quality of the induced callus. Leaf explants induce embryogenic calli at the highest frequency of $22.67 \pm 1.354$ compared to stem explants frequency of $17.67 \pm 1.213$. Most importantly, the highest number of shoots regenerated emerged from embryogenic calli of leaf explants. These findings conform to the report by Sefasi et al. (2012) who reported high frequency of embryogenic calli formation from leaf with petiole explants.

The frequencies of transformation and regeneration were obtained when the two types of explants were evaluated differently and significantly. Leaf explants responded well to both regeneration and transformation. This variation could be seen in the difference in the morphological structures and stages of maturity of the explants (Anwar et al. 2010). Before infection and cocultivation, explants were punctured with forceps to improve the infection process. When punctured, the explant stem produced latex which may have inhibited the effective infection by Agrobacterium. The morphological nature of sweet potatoes was generally regarded as a recalcitrant species for regeneration and transformation. Although methods to generate transgenic sweet potato plants have been reported, transformation efficiencies are generally low, and success is limited to a small number of varieties (Kreuze et al. 2008). Transgenic sweet potato plants were obtained from the Jewel (non-African) variety and Kemb36 by $A$. tumefaciens-mediated transformation and somatic embryogenesis regeneration. Initial transformation was done using pSARK-IPT gene construct.

Embryonic structures appeared in embryo maturation media, but interestingly, at this stage over-proliferation of roots from some callus material that did not form embryogenic tissues was noted. This could be attributed to the presence of high levels of auxins, specifically NAA in the explanted organs (George et al. 2008). Somatic embryos regenerated into shoots at a frequency of $2.083 \%$ for Jewel variety and $0.833 \%$ for Kemb36 variety. The difference in regeneration frequency between the Jewel variety and Kemb36, is clearly genotype dependent as earlier reported by Kreuze et al. (2008); Santa Maria et al. (2009); Anwar et al. (2010) and Sefasi et al. (2012).

In all transformations, $30 \mathrm{~m} \mathrm{~g} / \mathrm{L}$ mannose was added to the embryo maturation medium to prevent regeneration of untransformed events. The addition of mannose caused evident stress to the embryos but still allowed for recovery of presumed transgenic lines. Two presumed lines were recovered, and PCR was used to confirm presence of the IPT gene. Transformation efficiency, estimated as independent transgenic lines obtained from the total number of explants infected with Agrobacterium was 2.083 \pm 1.193 and $0.833 \pm 0.833$ for Jewel and Kemb36 genotypes respectively.

Genotype-dependence for regeneration and transformation in sweet potato has previously been reported (Anwar et al. 2010; Sefasi et al. 2012). An efficient selection method is therefore required to produce transgenic plants. In previous reports, either neomycin phosphotransferase (npt) II or hygromycin phosphotransferase (hpt) (Newell et al. 1995; Gama et al. 1996; Moran et al. 1998; Otani et al. 1998) or even a combination of the two (Km-Hyg) (Song et al. 2004) have been used as the selectable marker genes for selecting transformed sweet potato cells. Choi et al. (2007) successfully regenerated herbicide resistant transgenic sweet potato plants through Agrobacterium-mediated transformation system.

The gene construction marker in this study is the phosphomannose isomerase (PMI) gene. Until now, the use of PMI genes as markers in sweet potatoes has not been found in any published literature. The determination of optimal mannose concentration to be used for the selection of presumed transformants was done by experimenting on sweet potato callus derived from leaf explants with various mannose concentrations, and it determined that the concentration of $30 \mathrm{~g} / \mathrm{L}$ mannose was optimum to select for altered cells. At this concentration, some non-altered calluses of all the 3 varieties of sweet potato did not grow and then subsequently died on the medium. During the study, callus cultured on mannose showed moderate proliferation, brown color, and reduced mass after a long (3 month) culture period compared to the untreated controls. However, there is no clear evidence of a deadly outcome that could be apparent. In addition, among the three varieties of sweet potatoes, different levels of sensitivity to mannose were documented with KSP36 as the most sensitive variety and Kemb36 as the most tolerant.

To clearly know the effect of mannose on altered sweet potato cells, it is recommended to use a subculture of transformed cells on a medium equipped with $30 \mathrm{~g} / \mathrm{L}$ mannose and performed at all stages of regeneration until plant buds. Vaccari and Martinelli (2009) also reported a similar effect of mannose in three important stages of development of transgenic grape. Although 14 presumed transgenic plants were successfully regenerated, only 6 were PCR positive so that high numbers escaped.

\section{Response of sweet potato to drought stress}

Enakayake, (1990) previously established that the effect of drought treatment on sweet potato is dependent on the growth stage that it coincides. Moreover, Placide et al. (2013) established that sweet potato is sensitive to drought stress during growth establishment, vine development and storage root initiation. Hence, to evaluate the effect of applying drought stress on the physiological and 
morphological parameters and yields of sweet potatoes, the application of drought stress was held to concur with the critical development stage and extended to harvest time.

Generally, all growth parameters in wild-type plants decreased significantly due to drought stress to confirm the vulnerability of sweet potato plants to high intensity of drought stress during the critical stage of plant formation and root initiation. It also shows that in the growth and development of sweet potatoes, water is very important because it serves as a solvent and a medium of chemical reaction, organic and inorganic dissolved transport, cell turgidity, transpiration, and photosynthesis. The results have shown that underwater deficit conditions, PSARKIPT expression increases drought tolerance in transgenic sweet potatoes. This finding is consistent with the findings by Rivero et al. (2007) and Peleg et al. (2011) who demonstrated that PSARK: : IPT enhanced drought tolerance in transgenic tobacco and rice respectively. Under normal conditions, morphological and physiological differences are not clearly demonstrated in both transgenic and wild species. This indicates that under normal conditions, the introduction of PSARK-IPT gene has an insignificant effect on the growth and development of normal plants. However, all growth parameters gain significant influence when in drought stress. Of which, the development of vines was impaired and the leaves turned yellow and finally fell off the plant. According to Lim et al. (2007), leaf yellowing is a convenient and visible indicator of leaf senescence, and it reflects chloroplast senescence of mesophyll cells which is the first step in senescence associated programmed cell death. This study shows the emergence of signs of aging in wild plants that are under heavy pressure two weeks after the onset of drought treatment. Leaves that begin to wither and withered leaves that turn yellow appear on wild plants while in transgenic plants are not found for the leaves remain green and look healthy. Delayed senescence of transgenic plants may be associated with expression of IPT genes by transgenic plants regulating cytokinin biosynthesis, thus delaying senescence due to drought and sustaining growth.

Along with the ongoing handling of drought, both transgenic and wild plants showed decrease in length of vine, length of internode, canopy (number of leaves and leaf area), the size and number of tubers and number of roots compared with well-watered controls. In the previous study, it was observed that water deficits reduced the number of leaves and tubers, the size and composition of roots and vines, and the acquisition of dry weight from shoots and roots (Pardales et al. 2000). Similarly, these results are consistent with findings by Saraswati et al. (2012) who observed that biomass and morphological properties decreased in response to drought stress.

Relative water content is a measure of water content in plants and delineates metabolic activity in tissues, so this is an important index for dehydration tolerance. In the early stages of leaf development, RWC of leaves is higher and decreases due to dry matter accumulation and leaves maturity (Anjum et al., 2011). Under normal conditions (without stress), the plants maintained high level of water content. Under condition of drought stress, RWC decreased significantly. In moderate water stress, RWC of tested plants declined slightly and continued to decline under severe drought stress. However, the reduction of RWC in transgenic plants is less than in wild-type plants. During rewatering period, transgenic crops recover much faster than wild species. Therefore, these results suggest that this increase might be caused by transgenic line leaves that express IPT genes.

Phytohormones play an important role in the growth and development of plants (Walter 2009). Plants have several hormones such as auxin, gibberellin, cytokinin, ethylene, brassinosteroid, jasmonate, abscisic acid (ABA), and salicylic acid. These hormones are thought to play a major role in water deficit stress. Subject to drought stress conditions, elevated ABA levels lead to stomata closure thus preventing water loss and regulating the expression of many genes associated with the stress response. Hormones such as brassinosteroids and jasmonates act in conjunction with ABA in promoting premature senescence and programmed cell death, whereas hormones like cytokines, auxins, and ethylene act conversely in response to water deficit deficits (Pinheiro and Chaves 2011). The level of cytokinin decreases in response to water deficit (Xu et al., 2012). Reduced levels of cytokines are accompanied by breakdown of proteins and destruction of photosynthetic machinery, which causes cell senescence and programmed cell death. In this study, transgenic plants showed an increase in all growth parameters compared to wild-type which indicates that IPT gene expression may have increased cytokinin availability so that overall growth of plant growth can be accomplished. This can happen because cytokinins play important roles such as controlling cell proliferation, shoot formation and branching as well as delaying senescence.

Chlorophyll is one of the main components of chloroplasts and plays a very important role in photosynthesis. Relative chlorophyll content has been used to determine the rate of photosynthesis in plants during the water deficit period. The decrease in chlorophyll levels under drought stress is considered a typical symptom of oxidative stress and this is because of photo-oxidation of pigment and chlorophyll degradation (Anjum et al. 2011). The performance of photosynthesis was analyzed by determining chlorophyll degradation under drought stress and normal conditions to evaluate the effect of water deficit on photosynthesis in PSARK-IPT transgenic plants. Under normal conditions, transgenic plants showed significant differences in chlorophyll a, b, and total chlorophyll. During this study, it was found that moderate stress had no serious effect on the photosynthesis activities on both transgenic crops and wild species. Plants under moderate drought stress maintained a high total chlorophyll content and chlorophyll b. This observation is consistent with findings by Van Heerden and Laurie, (2008) who reported that chlorophyll content was barely affected by moderate stress. The content of chlorophyll in both transgenic and wild species came to near normal level, after the watering was redone, although wild species reached this level 2 days later. The most likely reason for this was that the water potential did not fall below a sustainable level and thus the 
functional activity of the plant photosynthesis engine was not affected. Similarly, under a moderate groundwater deficit, photosynthetic depression might be caused by stomatal closure or restriction, but not because of biochemical reactions. Therefore, the plants recovered to the level of control after the stress condition was removed.

Severe and prolonged drought stress on wild species caused transgenic PSARK: IPT to show relatively higher level of chlorophyll content. This happened because transgenic plants effectively protected photosynthesis by efficiently scavenging for ROS so that during water deficit pressures, water could be used efficiently. After the watering was redone, stressed transgenic plants, and stressed wild plants could not be fully recovered from severe drought conditions even after 9 days of watering. It was possible that they needed more time to recover or the dissipation of PSII heat energy was very limited, due to PSII structure and functionality damage.

\section{Effect of drought stress on root and tuber formation}

This study has shown that pSARK-IPT gene expression under maturation and promoter controls activated enhanced drought tolerance promoters and therefore increased yields in transgenic sweet potatoes. This is consistent with reports from Peleg et al. (2011) and Qin et al. (2011) about rice and peanuts respectively. Compared to wild species, excessive sweet potatoes exposed to excessive IPT are found to be in larger and higher size under less irrigation. This significant difference will be associated with higher level of photosynthesis in transgenic sweet potatoes under limited water conditions due to conserved photosynthetic equipment and higher relative water content. Therefore, the higher yields are because of the increase in photosynthetic rate, stomatal conductance and transpiration thus backing up the presumed cytokinin-mediated protection of photosynthesis in transgenic plants.

\section{Conclusions}

The experiments conducted in this study were able to produce change and regeneration in the varieties of sweet potatoes. However, the change and frequency of sweet potato regeneration and efficiency through somatic embryogenesis still depend on genotype. This confirms previous findings by Anwar et al. (2010) that the sweet potato [Ipomoea batatas (L.) Lam] is recalcitrant to change and regeneration so that the existing regeneration and transformation protocols are highly-dependent in-vitro response genotypes. Of the two explants tested, leaf explant provides better response to change and regeneration than in other parts so that the best way of regenerating sweet potato is through somatic embryogenesis. This study shows that sweet potato tissue is quite sensitive to mannose as a source of carbohydrates, but the deadly effects of mannose cannot be clearly noted during the early stages of development and to observe the effects of mannose then a long period of culture is required. This research succeeded in developing transgenic sweet potato plant PSARK-IPT. Plants are shown to slow down aging due to drought, and to maintain relatively higher water content, chlorophyll content, good tuber formation and, generally to maintain better growth than wild types under drought stress conditions.

\section{REFERENCES}

Anjum SA, Wang LC, Farooq M, Hussain M, Xue LL, Zuo CM. 2011. Brassinolide application improves the drought tolerance in maize through modulation of enzymatic antioxidants and leaf gas exchange. Agron Crop Sci 10: 1111-1439.

Anwar N, Watanabe KN, Watanabe JA. 2010. Transgenic sweet potato expressing mammalian cytochrome P450. Plant Cell Tiss Organ Cult 105: 219-231.

Battisti DS, Naylor RL. 2009. Historical warnings of future food insecurity with unprecedented seasonal heat. Science 323: 240-244.

Boyer JS. 1982. Plant productivity and environment. Science 218: 443448.

Cao YJ, Wei Q, Liao Y, Ling H, Li SX, Xiang CB, Kuai BK. 2009. Ectopic overexpression of AtHDG11 in tall fescue resulted in enhanced tolerance to drought and salt stress. Plant Cell Rep 28: 579588.

Chen JH, Su TC, Lin HC, Huang JG, Lin HY. 2010. Expression of sweet potato cysteine protease SPCP2 altered developmental characteristics and stress responses in transgenic Arabidopsis plants. J Plant Physiol 167: 838-847.

Choi TJ, Aing K, Len SI, Wu CC, Chiang SF, Su CL. 2006. Regulation of phosphate homeostasis by micro-RNA in Arabidopsis. Plant Cell 18: 412-421

Dafny-Yelin M, Tzfira T. 2007. Delivery of Multiple Transgenes to Plant Cells. Plant Physiol 145: 1118-1128.

Ekanayake IJ. 1990. Evaluation of potato and sweet potato genotypes for drought resistance. International Sweet potato Center (CIP) Research Guide 19: 66-68).

FAOSTAT. 2010. Statistics databases and data-sets of the Food and Agriculture Organization of the United Nations. FAO, Rome, Italy.

FAOUN. 2010. Food Security statistics of the World 2010. FAO, Rome, Italy.

Gama MIC, Leite JRP, Cordeiro AR, Cantliffe DJ. 1996. Transgenic sweet potato plants obtained by Agrobacterium tumefaciens-mediated transformation. Plant Cell Tiss Organ Cult 46: 237-244.

George EF, Hall MA, de Klerk GJ. 2008. Plant propagation by tissue culture. Springer, Dordrecht, Nederland.

Halliwell B. 2007. Dietary polyphenols: good, bad, or indifferent for your health? Cardiovascular Res 73: 341-347.

Jewell CM, Bradley CC, Godwin DI. 2010. Transgenic Plants for Abiotic Stress Resistance. Springer-Verlag, Berlin.

Jiang Q, Zhang JY, Guo X, Bedair M, Sumner L, Bouton J, Wang ZY. 2010. Improvement of drought tolerance in white clover (Trifolium repens) by transgenic expression of a transcription factor gene WXP1. Funct Plant Biol 37: 157-165.

Kakimoto T. 2000). identification of plant Cytokinin Biosynthesis Enzymes as Dimethylallyl Diphosphate: ATP/ADP Isopentenyl transferases. Plant Cell Physiol 42 (8): 677-685.

Kim YC, Ahn OY, Kim HS, Kim HY, Lee SH, Catanach SA, Jacobs EMJ, Conner JA, Kwak S. 2010. The sweet potato IbMYB1 gene as a potential visible marker for sweet potato intragenic vector system. Physiologia Plantarum 139: 229-240.

Kim YH, Lim S, Yang KS, Kim CY, Kwon SY, Lee HS, Wang X, Zhou Z, Ma D, Yun DJ, Kwak SS. 2009. Expression of Arabidopsis NDPK2 increases antioxidant enzyme activities and enhances tolerance to multiple environmental stresses in transgenic sweet potato plants. Mol Breed 24: 233-244.

Kreuze JF, Klein IS, Lazaro MU, Chuquiyuri WC, Morgan GL, Mejía PGC, Ghislain M, Valkonen JPT. 2008. RNA silencing-mediated resistance to a crinivirus (Closteroviridae) in cultivated sweet potato (Ipomoea batatas L.) and development of sweet potato virus disease following coinfection with a potyvirus. Mol Plant Pathol 9: 589-598.

Lebot V. 2009. Sweet potato. In: Bradshaw JE (ed) Root and Tuber Crops. Springer Sciences and Business Media, Dordrecht, Nederland.

Lichtenthaler HK. 1987. Chlorophyll and Carotenoids: Pigments of photosynthetic biomembranes. Methods Enzymol 148: 350-382.

Lim PO, Kim HJ, Nam HG. 2007) Leaf senescence. Ann Rev Plant Biol 58: 115-136. 
Liu X, Hua X, Guo J, Qi D, Wang L, Liu Z, Jin Z, Chen S, Liu G. 2008 Enhanced tolerance to drought stress in transgenic tobacco plants overexpressing VTE1 for increased tocopherol production from Arabidopsis thaliana. Biotechnological letters 30: .1275-1280.

Long SP, Ort DR. 2010. More than taking the heat: crops and global change. Current. Opinions. Plant Biol 13: 241-248.

Lu YY, Deng XP, Kwak SS. 2010. Overexpression of CuZn superoxide dismutase (CuZn SOD) and ascorbate peroxidase (APX) in transgenic sweet potato enhances tolerance and recovery from drought stress. African J Biotechnol 9: 8378-8391.

Luceri C, Giovannelli L, Pitozzi V, Toti S, Castagnini C, Routaboul J M, Lepiniec L, Larrosa M, Dolara P. 2008. Liver and colon DNA oxidative damage and gene expression profiles of rats fed Arabidopsis thaliana mutant seeds containing contrasted flavonoids. Food Chem Toxicol 46: 1213-1220.

Luo HR, Santa Maria M, Benavides J, Zhang DP, Zhang YZ, Ghislain M. 2006. Rapid genetic transformation of sweet potato (Ipomoea batatas (L.) Lam) via organogenesis. African J Biotechnol 5: 1851-1857.

Mervat MM, El Far K, Mangoury E, Elazab HEM. 2009. Novel Plant Regeneration for Egyptian Sweet potato (Ipomoea batatas (L.) Lam.) Abees Cultivar via Indirect Organogenesis Stimulated by Initiation Medium and Cytokinin Effects. Australian J Basic Appl Sci 3 (2): 543-551.

Moran R, García R, López A, Zaldua Z, Mena J, Garcia M, Armas R, Somonte D, Rodriguez J, Gomez M, Pimentel E. 1998. Transgenic sweet potato plants carrying the delta-endotoxin gene from Bacillus thuringiensis var. tenebrionis. Plant Sci 139: 175-184.

Newell CA, Lowe JM, Merryweather A, Booke LM, Hamilton WDO. 1995. Transformation of sweet potato (Ipomoea batatas (L.) Lam.) with Agrobacterium tumefaciens and regeneration of plants expressing cowpea trypsin inhibitor and snowdrop lectin. Plant Sci 107: 215-227.

Njagi IW. 2004. Optimization of parameters for Agrobacterium-Mediated transformation of sweet potato,

Otani M, Shimada T, Kimura T, Saito A. 1998. Transgenic plant production from embryogenic callus of sweet potato (Ipomoea batatas (L.) Lam.) using Agrobacterium tumefaciens. Plant Biotechnol 15: 11-16.

Pardales J, Bañoc DM, Yamauchi A, Iijima M, Esquibel C. 2000. The effect of fluctuations of soil moisture on root development during the establishment phase of sweet potato. Plant Prod Sci Tokyo 3 (2): 134 139.

Peleg Z, Reguera M, Walia H, Blumwald E. 2011. Cytokinin mediated source-sink modifications improve drought tolerance and increase grain yield in rice under water stress. Plant Biotechnol 9: 747-758.

Pennisi E. 2008. The blue revolution, drop by drop, gene by gene. Science 320: 171-173.

Pinheiro C, Chaves MM. 2011. Photosynthesis and drought: Can we make metabolic connections from available data. J Exp Bot 62 (3): 869-882.

Placide R, Shimelis H, Laing M, Gahakwa D. 2013. Physiological mechanisms and conventional breeding of sweet potato (Ipomoea batatas (L.) Lam.) to drought tolerance. African J Biotechnol 8 (18): 1837-1846.

Qin H, Gu Q, Zhang J, Sun L, Kuppu S. 2011. Regulated expression of an isopentenyl transferase gene (IPT) in peanuts significantly improves drought tolerance and increases yield under field conditions. Plant Cell Physiol 52: 1904-1914.

Rivero MR, Gimeno J, Van Deynze A, Walia H, Blumwald E. 2010. Enhanced Cytokinin Synthesis in Tobacco Plants Expressing P SARK
: IPT Prevents the Degradation of Photosynthetic Protein Complexes During Drought. Plant Cell Physiol 51: 1929-1941.

Rivero RM, Shulaev V, Blumwald E. 2009. Cytokinin-dependent photorespiration and the protection of photosynthesis during water deficit. Plant Physiol 150: 1380-1393.

Rivero RM, Kojima M, Gepstein A, Sakakibara H, Mittler R, Gepstein S, Blumwald E. 2007. Delayed leaf senescence induces extreme drought tolerance in a flowering plant. Proc Natl Acad Sci USA 104 (49): 19631-19636.

Santa-Maria M, Kenneth V, Pecota KV, Yencho CG, Allen G, Sosinski B. 2009. Rapid shoot regeneration in industrial 'high starch' sweet potato (Ipomoea batatas L.) genotypes. Plant Cell Tiss Organ Cult 109: 109-117.

Saraswati P, Purnomo DW, Mawikere LN. 2012. The effectiveness of AM fungal in improving the tolerance of sweet potato plants to drought stress. International Conference on Agricultural, Environment and Biological Sciences

Sefasi A, Kreuze J, Ghislain M, Manrique S, Kiggundu A, Semakula G, Mukasa S B. 2012. Induction of somatic embryogenesis in recalcitrant sweet potato (Ipomoea batatas L.) cultivars. African J Biotechnol 11 (94): 16055-16064.

Shinozaki K, Yamaguchi-Shinozaki K. 2007. Gene networks involved in drought stress response and tolerance. J Exp Bot 58: 221-227.

Song GQ, Honda H, Yamaguchi K. 2004). Efficient Agrobacterium tumefaciens-mediated transformation of sweet potato (Ipomoea batatas (L.) Lam) from stem explants using a two-step kanamycinhygromycin selection method. In-vitro Cell Dev Biol Plants 40: 359365 .

Teow CC, Truong VD, Mcfeeters RF, Thompson RL, Pecota KV, Yencho GC. 2007. Antioxidant activities, phenolic and $\beta$-carotene contents of sweet potato genotypes with varying flesh colours. J Food Chem 103: 829-838.

Umezawa T, Fujita M, Fujita Y, Yamaguchi-Shinozaki K, Shinozaki K. 2006. Engineering drought tolerance in plants: discovering and tailoring genes to unlock the future. Curr Opin Biotechnol 17: 113122.

Vaccari I, Martinelli L. 2009. Evaluation of the phosphomannose isomerase-based selection system for gene transfer in grape. Vitis 48: 137-144.

Van Heerden PDR, Laurie R. 2008. Effects of prolonged restriction in water supply on photosynthesis, shoot development and storage root yield in sweet potato. Physiologia Plantarum 134 (1): 99-109.

Walter A, Silk WK, Schurr U. 2009. Environmental effects on spatial and temporal patterns of leaf and root growth. Ann Rev Plant Biol 60: 279-304.

Wang CR, Yang AF, Yue GD, Gao Q, Yin HY, Zhang JR. 2008. Enhanced expression of phospholipase C 1 (ZmPLC1) improves drought tolerance in transgenic maize. Planta 227: 1127-1140.

Xu ZY, Lee KH, Dong T. 2012. A vacuolar beta-glucosidase homolog that possesses glucose conjugated abscisic acid hydrolyzing activity play an important role in osmotic stress responses in Arabidopsis. Plant Cell 24: 2184-2199.

Yang S, Vanderbeld B, Wan J, Huang1 Y. 2010. Narrowing down the targets: towards successful genetic engineering of drought-tolerant crops. Molecular Plant 3: 469-490.

Zidani S, Ferchichi A, Chaieb M. 2005. Genomic DNA extraction method from pearl millet (Pennisetum glaucum) leaves. African J Biotechnol 4 (8): 862-866. 